\title{
Correction to: Inpatient versus outpatient induction of labour: a systematic review and metaanalysis
}

\author{
Susan Dong ${ }^{1,2}$, Maria Khan ${ }^{1}$, Farahnosh Hashimi ${ }^{1}$, Caroline Chamy ${ }^{3}$ and Rohan D'Souza ${ }^{1,4,5^{*}}$
}

\section{Correction to: BMC Pregnancy Childbirth 20, 382 (2020) \\ https://doi.org/10.1186/s12884-020-03060-1}

Following publication of the original article [1], the authors identified an error in Fig. 3. The correct figure is given below.

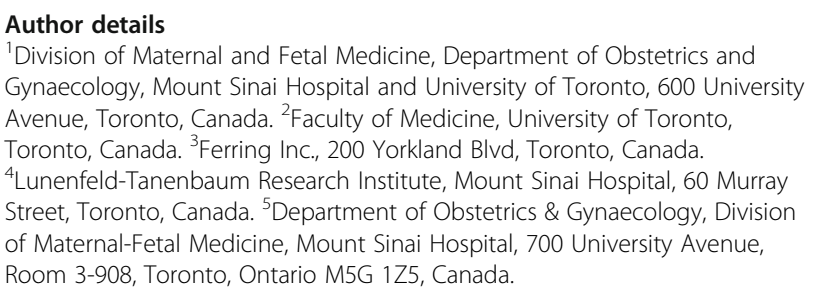

'Division of Maternal and Fetal Medicine, Department of Obstetrics and Gynaecology, Mount Sinai Hospital and University of Toronto, 600 University Avenue, Toronto, Canada. ${ }^{2}$ Faculty of Medicine, University of Toronto, Toronto, Canada. ${ }^{3}$ Ferring Inc., 200 Yorkland Blvd, Toronto, Canada. ${ }^{4}$ Lunenfeld-Tanenbaum Research Institute, Mount Sinai Hospital, 60 Murray Street, Toronto, Canada. ${ }^{5}$ Department of Obstetrics \& Gynaecology, Division of Maternal-Fetal Medicine, Mount Sinai Hospital, 700 University Avenue, Room 3-908, Toronto, Ontario M5G 125, Canada.

Published online: 13 July 2020

\section{Reference}

1. Dong, et al. Inpatient versus outpatient induction of labour: a systematic review and meta-analysis. BMC Pregnancy Childbirth. 2020;20:382 https:// doi.org/10.1186/s12884-020-03060-1.

\footnotetext{
The original article can be found online at https://doi.org/10.1186/s12884020-03060-1.

* Correspondence: Rohan.DSouza@sinaihealthsystem.ca

'Division of Maternal and Fetal Medicine, Department of Obstetrics and

Gynaecology, Mount Sinai Hospital and University of Toronto, 600 University Avenue, Toronto, Canada

${ }^{4}$ Lunenfeld-Tanenbaum Research Institute, Mount Sinai Hospital, 60 Murray Street, Toronto, Canada
}

Full list of author information is available at the end of the article

(c) The Author(s). 2020 Open Access This article is licensed under a Creative Commons Attribution 4.0 International License, which permits use, sharing, adaptation, distribution and reproduction in any medium or format, as long as you give appropriate credit to the original author(s) and the source, provide a link to the Creative Commons licence, and indicate if changes were made. The images or other third party material in this article are included in the article's Creative Commons licence, unless indicated otherwise in a credit line to the material. If material is not included in the article's Creative Commons licence and your intended use is not permitted by statutory regulation or exceeds the permitted use, you will need to obtain permission directly from the copyright holder. To view a copy of this licence, visit http://creativecommons.org/licenses/by/4.0/ The Creative Commons Public Domain Dedication waiver (http://creativecommons.org/publicdomain/zero/1.0/) applies to the data made available in this article, unless otherwise stated in a credit line to the data. 


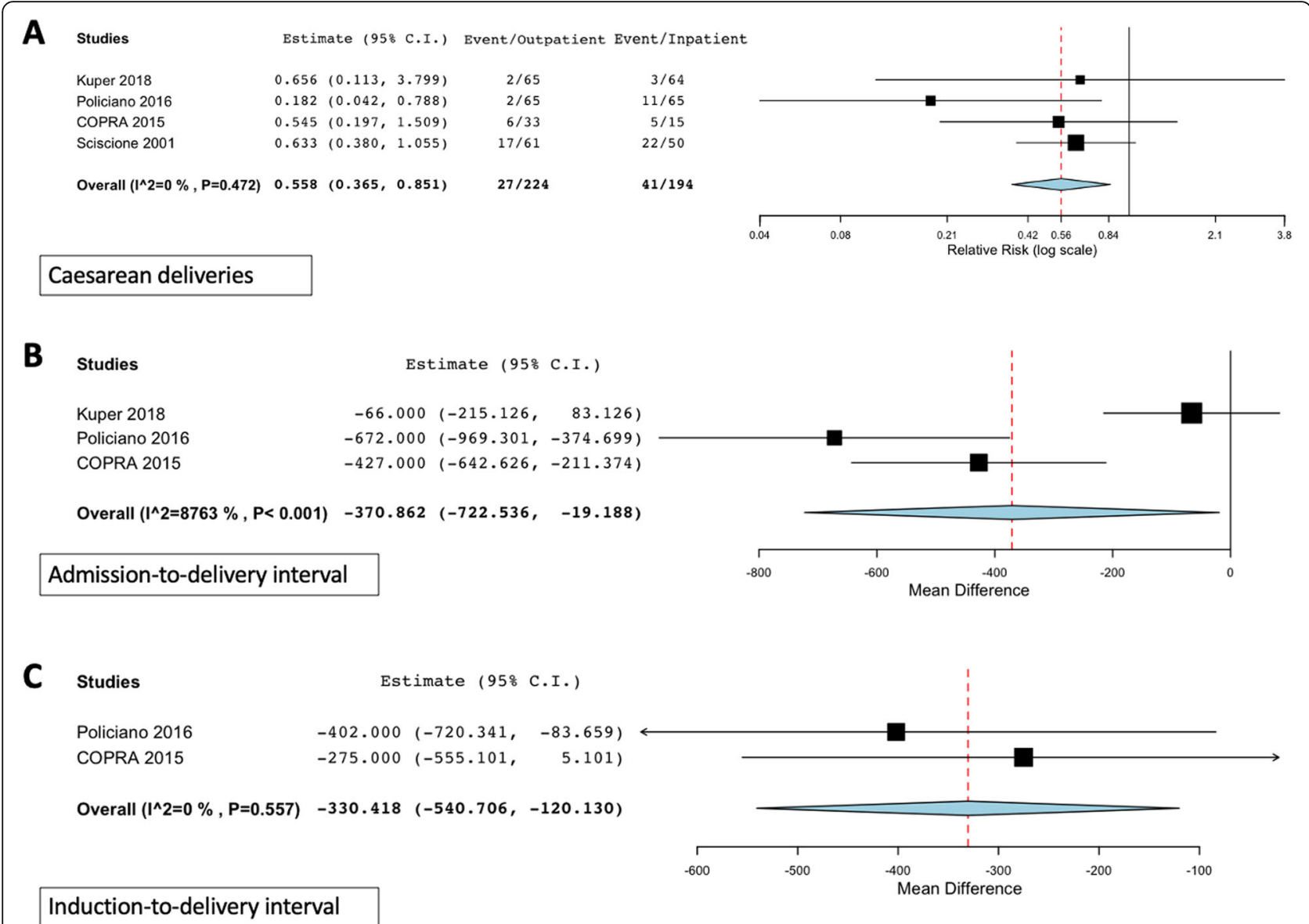

Fig. 3 Subgroup analysis: Significant outcomes in trials where balloon catheters were used in both arms. [COPRA, Comparison of Inpatient with outpatient Balloon Catheter Cervical Ripening] 